\title{
Calculation of magnetic field intensity under power line with taking into account conductor sag
}

\author{
Krzysztof Król ${ }^{1, *}$, Krzysztof Budnik ${ }^{1}$, and Piotr Jarek ${ }^{1}$ \\ ${ }^{1}$ Poznań University of Technology, Institute of Electrical Engineering and Electronics, Piotrowo 3A, 60-965 Poznań, Poland
}

\begin{abstract}
The paper presents a calculation method of the magnetic field under an overhead power line taking into account conductor sag, which is described by the catenary curve. The calculations take into account the variability of the charge distribution along the conductor and wire sag for the eclectic field, while the calculation of intensity of the magnetic field take into account the impact of induced currents in the wires of lightning. The simulation results were compared with results measurements.
\end{abstract}

\section{Introduction}

Transmission lines are used to transfer the electric energy for a long distance transmission between substations. Power lines, generate magnetic fields that adversely affect living organisms. The intensity of the magnetic field depends on the current flowing in the phase conductors, currents induced in the earth wires, and wires deployment, wire suspension height, conductor lengths.

Several publications calculated the magnetic fields created by power transmission lines assume that lines are parallel to a flat ground and the sag is neglected or introduced by taking an effective or average height in between the maximum and the minimum height of the line $[2,3]$.

The paper presents method of calculation the magnetic field intensity with taking into account sag conductors and comparison of calculation results with measurement results $[2,3]$.

\section{Intensity of the magnetic fields of a power line including the sag of wires}

To take into account the sag in the calculations, divide a conductor of a span which are between the spans into $n$ equal segments $\left(s_{1}, s_{2}, \ldots s_{i-1}, s_{i}, s_{i+1}, s_{n}\right)$ as Figure 1 shows. $H$ is the maximum height of the conductors suspension, $\mathrm{h}$ is the minimum height of the conductors suspension in the middle of the span, $S$ is the conductor sag, $S=H-h$. The calculation should assume the principle that the number of simulated charges must correspond to the number of defined segments.

Each of the segments $\left(s_{1}, \ldots, s_{n}\right)$ can be described by the curve equation $[3,4]$ :

$$
z^{\prime}\left(x^{\prime}\right)=h+2 \alpha \sinh ^{2}\left(\frac{x^{\prime}}{2 \alpha}\right)
$$

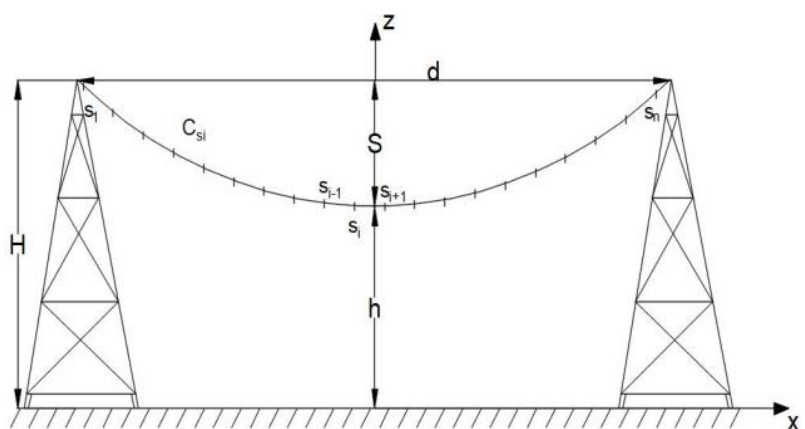

Fig. 1. The power line conductor division of into $n$ segments.

where $\alpha$ is related to the mechanical parameters of the line: $\alpha=T_{h} / w . T_{h}$ is the mechanical stresses in the middle of the line, $w$ is the weight per unit of the length of the line.

Magnetic field of a power line is produced by currents flowing in phase coductors as well as in earth wires. Method for calculating induced currents in earth wires was taken from [1], which uses the complex ground return plane approach. The current induced in earth wires in case of two earth wires $\mu$ and $v$ can be calculated from the relation:

$$
\left[\begin{array}{c}
I_{\mu} \\
I_{v}
\end{array}\right]=-\left[\begin{array}{cc}
Z_{\mu} & Z_{\mu v} \\
Z_{v \mu} & Z_{v}
\end{array}\right]^{-1}\left[\begin{array}{lll}
Z_{1 \mu} & Z_{2 \mu} & Z_{3 \mu} \\
Z_{1 v} & Z_{2 v} & Z_{3 v}
\end{array}\right]\left[\begin{array}{c}
I_{1} \\
I_{2} \\
I_{3}
\end{array}\right]
$$

where $I_{\mu}, I_{v}$ - currents (phasors) induced in earth wires $\mu$ and $v, I_{1}, I_{2}, I_{3}$ - phasors of the phase currents of the power line, $\left(Z_{k}, Z_{l}\right)-Z_{s}$ self-complex impedance of the earth wire calculated from equations:

$$
Z_{s}=j \omega \frac{\mu_{0}}{2 \pi} \ln \frac{2(h+p)}{r}
$$

where $h$ - height of earth wire, $r$ - wire radius,

$$
p=\frac{1}{\sqrt{j \omega \mu_{0} \gamma}}=\frac{\delta_{S}}{2}(1-j)
$$




$$
\delta_{S}=\frac{1}{\sqrt{\pi f \mu_{0} \gamma}}
$$

and $\gamma$ - ground conductivity, $f$ - frequency.

Mutual complex impedances between earth wires $k$ and $l,\left(Z_{m}\right)$ can be obtained from the equation:

$$
\begin{gathered}
Z_{m}=j \omega \frac{\mu_{0}}{2 \pi} \ln \frac{g}{a} \\
g=\sqrt{\left(h_{k}+h_{l}+2 p\right)^{2}+d_{k l}^{2}} \\
a=\sqrt{\left(h_{k}-h_{l}\right)^{2}+d_{k l}^{2}}
\end{gathered}
$$

where $d_{k l}$ - distance between the earth wires $k$ and $l, h_{k}, h_{l}$ - height of earth wire $k$ and $l$. The magnetic flux density produced by current in a single sagging coductor can be calculated using the Biot-Savart's law $[3,5]$ :

$$
\boldsymbol{B}\left(r^{\prime}\right)=\mu_{0}\left(\int_{C_{s i}} \frac{I\left(l_{s i}^{\prime}\right)\left[d \boldsymbol{l}_{s i}^{\prime} \times \boldsymbol{R}\left(l_{s i}^{\prime}\right)\right]}{4 \pi \mid \boldsymbol{R}_{s i}\left(l_{s i}^{\prime}\right)^{2}}\right)
$$

where $\mu_{0}=4 \pi \cdot 10-7 \mathrm{H} / \mathrm{m}$ is the magnetic permeability of the vacuum $I\left(l_{s i}^{\prime}\right)$, - current, $\boldsymbol{R}_{s i}\left(l_{s i}^{\prime}\right)$ is a vector from the source point, $\boldsymbol{R}\left(l_{s i}^{\prime}\right)$ is a unit vector in the direction of $\boldsymbol{R}_{\boldsymbol{s i}}\left(l_{s i}^{\prime}\right)$ as shown in Fig. 2.

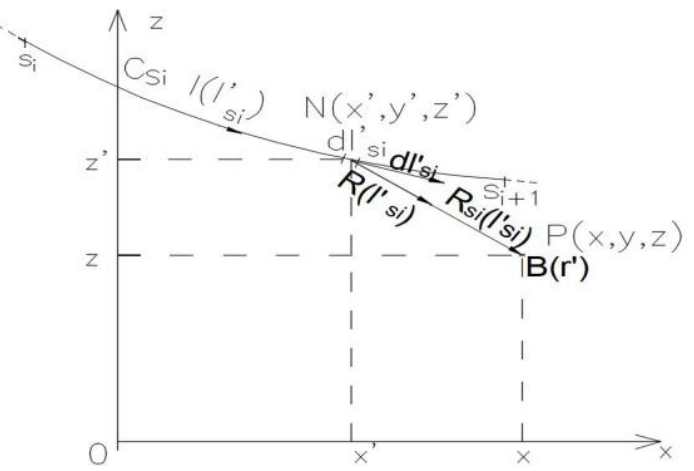

Fig. 2. Segment of the power line conductor - consider system.

The intensity of the magnetic field at any point above the earth's surface is determined from relation [3]:

$$
\boldsymbol{H}(x, y, z)=\frac{I}{4 \pi}\left[\int_{-d / 2}^{d / 2} \frac{\left[\left(x-x^{\prime}\right) \boldsymbol{a}_{x}+\left(y-y^{\prime}\right) \boldsymbol{a}_{y}+\left(z-z^{\prime}\right) \boldsymbol{a}_{z}\right] \cosh \left(\frac{x^{\prime}}{\alpha}\right)}{\left(\sqrt{\left(x-x^{\prime}\right)^{2}+\left(y-y^{\prime}\right)^{2}+\left(z-z^{\prime}\right)^{2}}\right)^{3}} d x^{\prime}\right]
$$

The total magnetic field is calculated from the vector summation of the fields from currents in all the transmission-line conductors $[3,5]$ :

$$
H_{T}=\sqrt{\sum_{m=1}^{M} H_{x}^{2}+\sum_{m=1}^{M} H_{y}^{2}+\sum_{m=1}^{M} H_{z}^{2}}
$$

\section{Example}

Measurements of magnetic field intensity were made with 3D E / $\mathrm{H}$ meter type of ESM-100. The device measures the field of the electric and magnetic intensities in real time and regardless of its direction. ESM-100 has six-channel measurements (Bx, By, Bz and Ex, Ey, Ez), while the resolution of the meter is determined at $1 \mathrm{nT}$ and $100 \mathrm{mV}$.
The research object was a $110 \mathrm{kV}$ line in the city Poznań on Nadwarciańska street, about half a kilometre from the GPZ station in the Czerwonak. The towers are type of the B2, voltage configuration $\underline{U}_{I}=110 \mathrm{e}^{-\mathrm{j} 120^{\circ}} \mathrm{kV}$, $\underline{U}_{2}=110 \mathrm{kV}, \underline{U}_{3}=110 \mathrm{e}^{\mathrm{j} 120^{\circ}} \mathrm{kV}$. The length between towers is 300 meters. The current during the measurements was $235 \mathrm{~A}$.

Table 1 presents calculated earth wire currents and

\begin{tabular}{|c|c|c|c|c|c|}
\hline $\begin{array}{c}\mathrm{h}_{\mathrm{L} 1, \mathrm{~L} 2} \\
{[\mathrm{~m}]}\end{array}$ & $\begin{array}{l}\mathrm{h}_{\mathrm{L} 3} \\
{[\mathrm{~m}]}\end{array}$ & $\begin{array}{l}\mathrm{h}_{\mathrm{e}} \\
{[\mathrm{m}]}\end{array}$ & $\mathrm{I}_{\mathrm{e}}[\mathrm{A}]$ & $\begin{array}{l}\mathrm{H}_{\mathrm{T} \max } \\
{[\mathrm{A} / \mathrm{m}]}\end{array}$ & $\begin{array}{c}\mathrm{H}_{\text {measure max }} \\
{[\mathrm{A} / \mathrm{m}]}\end{array}$ \\
\hline 5,85 & 9,15 & 12,15 & \multirow{4}{*}{$\begin{array}{c}-16,04- \\
\text { j0,04 }\end{array}$} & 8,52 & \multirow{4}{*}{3,05} \\
\hline 7 & 9 & 11 & & 6,16 & \\
\hline 8 & 10 & 12 & & 4,73 & \\
\hline 9 & 11 & 13 & & 3,68 & \\
\hline
\end{tabular}
the maximum magnetic field intensity calculated for conductors on different heights $\left(h_{L 1}, h_{L 2}, h_{L 3}, h_{e}\right)$ in the middle of the span. Fig. 3 present comparison of calculated results magnetic intensity using of method CSM with result measurements made under the line.

Table 1. Calculation results.

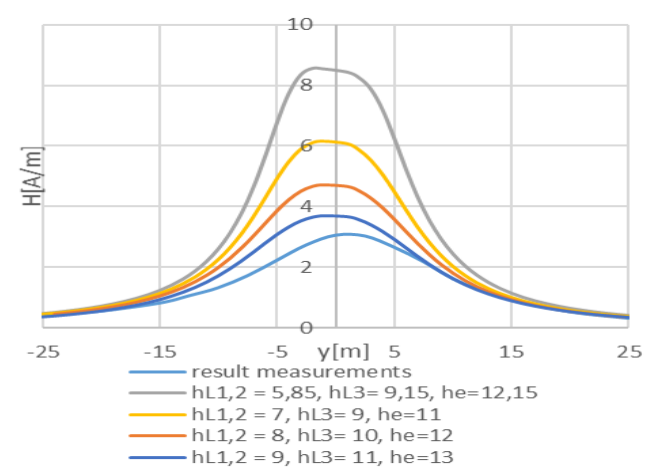

Fig. 3. Magnetic field strength charts - comparison of measurements with calculation method.

\section{Conclusions}

It is difficult to measure the height of the conductors - in the middle of the span, and this height influences magnetic field intensity under the power line.

The current measurement was obtained from the power industry in Poznań.

The presented method allows calculation fields magnetic intensity consistent with the results measured for the power line. The observation point in the calculations is at a height of $2 \mathrm{~m}$ above the ground in according to with the standard PN-EN 50341.

\section{References}

1. A. Deri, G. Tevan, A. Semlyen, A. Castanheira, IEEE Transactions on Power Apparatus and Systems, 100 (1981)

2. Z. Nadolny, A. Rakowska, Prz. Elektrotech. 86, 5 (2010)

3. K. Król, K. Budnik, P. Jarek, Electrical Engineering 93, (2018)

4. J. C. Fernandez, H. L. Soibelzon, EMC Europe 2002

5. M. Krakowski, Elektrotechnika Teoretyczna, t. 2. PWN (1995) 